\title{
2D Numerical Study of Heat Transfer Enhancement Using Fish-Tail Locomotion Vortex Generators
}

\author{
Ahmed Hashim Yousif ${ }^{1}$, Hakim T. Kadhim ${ }^{1 *}$, Kadhim K. Idan Al-Chlaihawi ${ }^{2}$ \\ ${ }^{1}$ Mechanical Department, Technical Institute of Al-Diwaniyah, Al-Furat Al-Awsat Technical University (ATU), Al- Qadisiyah \\ 58001, Iraq \\ ${ }^{2}$ Department of Mechanical Engineering, Collage of Engineering, University of Al- Qadisiyah, Al- Qadisiyah 58002, Iraq
}

Corresponding Author Email: dw.hkm@atu.edu.iq

https://doi.org/10.18280/mmep.080307

Received: 20 January 2021

Accepted: 3 March 2021

\section{Keywords:}

$2 D$ simulation, convection heat transfer, vortex generator, fish-tail locomotion

\begin{abstract}
In this paper, a numerical simulation is performed to study the effect of two types of concave vortex generators (VGs), arranged as fish-tail locomotion in a rectangular channel. The heat transfer and fluid flow characteristics with and without VGs are examined over the Reynolds number range $200 \leq R e \leq 2200$. The two proposed types of the VGs are selected based on the speed of the fish movement which is arranged in different distances between them $(\mathrm{d} / \mathrm{H}=0.6,1,1.3)$. The results show that the use of VGs can significantly enhance the heat transfer rate, but also increases the friction factor. The heat transfer performance is enhanced by $(4-21.1 \%)$ reaching the maximum value by using the first type of the VGs at $(d / H=1.3)$ due to better mixing of secondary flow and the new arrangement of the VGs which lead to decreasing the friction factor with an easy flow of fluid.
\end{abstract}

\section{INTRODUCTION}

The study of enhancing convective heat transfer using vortex generators (VGs) has been performed in many industries involving gas to liquid and gas to gas heat transfer [1]. Longitudinal VGs are divided into multi types such as delta wing, rectangular wing, delta winglet, rectangular winglet, etc. which are used for various applications. Considering the air as working fluid, the convection thermal resistance is the dominant part of heat transfer and efforts should be made essentially on surfaces that are in contact with air movement [2]. The effects of a combination of VGs and dimples on a microchannel heat sink with a constant heat flux over $R e$ ranges of 167-834 was studied by Gaofend and Zhai [3]. The result indicates that the use of VGs and dimples could enhance the heat transfer performance by $23.4-59.8 \%$ with a penalty of apparent friction factor which increased by 22.154.4. Nfawa et al. [4] studied heat transfer and flow behaviour of water inside a corrugated channel with a new configuration of winglet VG over $R e$ ranged from 5000-17500. The findings showed that the use of longitudinal VG in corrugated duct results in an improvement in the heat transfer accompanied with increasing the skin friction factor over those of a plane duct. Consequently, a winglet longitudinal vortex-generator with a corrugated channel might be favorable in heat transfer. Eibeck and Eaton [5] investigated experimentally the impact of a single longitudinal vortex in turbulent boundary layer. Little effect on heat transfer was observed due to the distortion of the turbulence field. Biswas and Chattopadhyay [6] examined numerically the effect of the hole geometry under delta wing VG with $R e$ of 500 on heat transfer rate. The results showed that using wing VG lead to increasing Nusselt number and friction factor by $34 \%$ and $79 \%$ respectively. An experimental study on the impact of using VGs in a channel on heat transfer performance was carried out by Mitra and Fiebig [7] and Wang et al. [8]. It was pointed out that the use of VGs heat transfer improved accompanied with an increase in the pressure drop. Numerical studies by Wu and Tao $[9,10]$ investigated the effect of using punching rectangular and triangular winglets VGs on laminar natural convection heat transfer. The authors reported that heat transfer was enhanced strongly with a low coefficient of friction near the winglets. Tang et al. [11] introduced a new configuration of winglets VG showing its effect on heat transfer and flow losses. It was found that heat transfer was enhanced with low-pressure drop. Oneissi et al. [12] studied the characteristic of turbulent flow and heat transfer using a novel combination of winglets. They found that heat transfer and friction factor increased by 2.1 $20.7 \%$ and $4.7-104 \%$ respectively.

He [13] used a new delta-winglet array to enhance heat transfer, deployed in (V) shape at $15^{\circ}, 30^{\circ}$, and $45^{\circ}$ over $R e$ ranges of 340 to 940 . The results showed that the heat transfer rate can be enhanced by (14-30\%). Marku and Lars [14] numerically investigated the enhancement in heat transfer in the heat exchanger channel for aircraft application by using flow-manipulating devices. A numerical investigation and optimal configuration of $\mathrm{VG}$ in plate-fin channel over $R e$ ranges of (380-1140) was implemented by Tariq and $\mathrm{Li}$ [15]. They showed that the heat transfer rate increases with a decrease in the pressure drop by increasing the angle of attack to a certain value between $45^{\circ}$ and $60^{\circ}$. Maniar [16] investigated the effect of vortex generators at $(500 \leq R e \leq 7000)$ in a rectangular channel. The results showed that the maximum Nusselt number is achieved when the angle of attack is $29^{\circ}$. Bayareh et al. [17] studied the effect of angle of a triangular vortex generator for laminar flow on enhancing 
heat transfer in a channel. The authors indicated that the heat transfer performance is considerably affected by increasing the angle from $30^{\circ}$ to $90^{\circ}$. Syaiful et al. [18] performed an experimental investigation aimed to show the effect of combined wedge ribs and winglet VGs on heat transfer and friction factor. The arrangement of VGs placed inside the channel wall is staggered and inline array with the angle of attack of $60^{\circ}$. It was found that the heat transfer rate inline array is much higher than the staggering array. Another experimental study is implemented by Syaiful et al. [19] to show the effect of two types of VGs on heat transfer. Both types of VGs are placed in an inline position at angle of attack of $30^{\circ}$. The results showed that three-row of concave rectangular winglet gives the best heat transfer accompanied with a decrease in thermal resistance. More experimental studies dealing with the effect of various geometries and angle of attack of VGs on heat transfer and pressure drop characteristics are reported in references [20,21].

There are several previous studies carried out using nanofluids with a vortex generator to determine their effect on the heat transfer process. Zheng et al. [22] investigated numerically the flow and heat transfer characteristics using water/DWCNT- $-\mathrm{TiO}_{2}$ hybrid nanofluid, in a rectangular channel with semi-circular and triangular VGs. The results illustrated that heat transfer was enhanced by increasing $R e$ and the volume fraction. The use of semi-circular VG gives higher heat transfer compared to the triangular VG. Ahmed et al. [23] studied laminar flow and heat transfer with different nanofluids inside the triangular duct with VGs at Re ranges of (100-800). The results showed that the use of $\mathrm{SiO}_{2}-\mathrm{EG}$ at a volume fraction of $6 \%$ and $R e$ of 800 results in a higher average Nusselt number of about $50 \%$ compared to the case of using $R e=100$. Other interesting analysis of the effect of different techniques with and without nanofluids on enhancing heat transfer can be found in references [24-26].
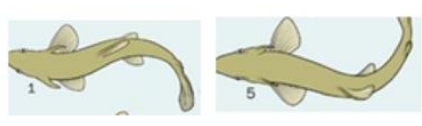

(a)
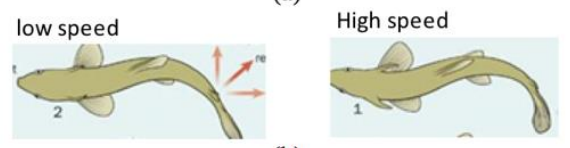

(b)

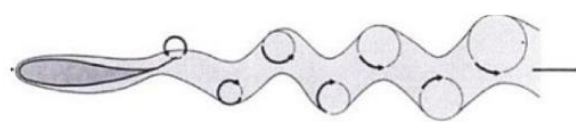

(c)

Figure 1. Fish movement, (a) swimming process of fish (b) Shape of the fish tail based on the swimming speed of fish,

(c) 2-D view of wakes behind a swimming fish

Many studies investigated the effect of hydrodynamics on fish locomotion. A fish-like undulating body was proposed by Namshad et al. [27] as it is an efficient propulsion system. The impact of the wavelength of the undulation was investigated theoretically at $R e$ of 4000 with an in-house 2D code utilizing level-set immersed boundary-method. It was found that the larger wavelength of the undulating motion is preferred for the use of larger thrust generation while the smaller wavelength is used for applications that required smaller thrust force. Gang et al. [28] used a numerical model to predict the swimming movement of fish establishing based on to the real locomotion of (tuna). A kinematic model for the simulation of tuna fish movement was proposed and the boundary conditions were verified by experiments with a set of force measuring devices and a physical fish-like prototype. The results illustrated that the coefficient of the averaged drag force reduces as the fishlike model speed up due to the pressure of water close the fish head strengthens generating a considerable resistance and the wake field vortex disperses producing a lower positive impact.

Figures 1(a), 1(b) and 1(c) show respectively the swimming process of the fish, the shape of the fish tail according to the swimming speed and the vortices generated due to the fish movement. In this paper, a numerical simulation of new types of concave VGs, based on the fish-tail locomotion, in a rectangular channel is introduced. The geometry of the proposed VGs are dependent on the speed of fish movement in the water and the fish-tail force hitting the water. To the authors' best knowledge, no work is reported to date addressing the impacts of using fish-tail locomotion vortex generators in a rectangle channel on the heat transfer and pressure drop characteristics. In addition, the impact of various inline arrangements of these VGs is investigated. Therefore, the current study gives an original contribution related to different industrial applications.

\section{METHODOLOGY}

The physical model of this study consists of a rectangular channel with the proposed two types of concave vortex generators that are located in an inline arrangement as illustrated in Figure 2.
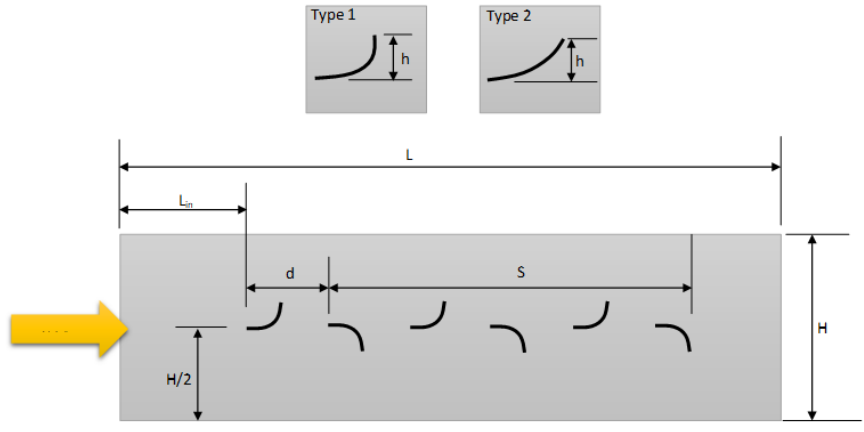

Figure 2. Details of the geometry of the present study

The proposed VGs, shown above in Figure 2 as type 1 and type 2 , represent respectively the high speed and low speed of a swimming fish. The model parameters of the considered geometry were with respect to the height of channel $(\mathrm{H})$ as follows: $\mathrm{L} / \mathrm{H}=50, \mathrm{Lin} / \mathrm{H}=1.5, \mathrm{~h} / \mathrm{H}=0.22$ and $\mathrm{d} / \mathrm{H}=0.6,1$ and 1.3. In addition, both the top and bottom walls are exposed to a constant wall temperature. The governing equations are written as in [29]:

$$
\frac{\partial(u \varphi)}{\partial x}+\frac{\partial(v \varphi)}{\partial y}=\frac{\partial}{\partial x}\left(\Lambda_{\varphi} \frac{\partial \varphi}{\partial x}\right)+\frac{\partial}{\partial y}\left(\Lambda_{\varphi} \frac{\partial \varphi}{\partial y}\right)+S_{\varphi}
$$

As shown in Table 1, $\varphi$ is a dependent parameter $\mathrm{u}, \mathrm{v}$ and $\mathrm{T}$ also, $S_{\varphi}$ and $\Lambda_{\varphi}$ represent the source terms and diffusion coefficient respectively.

In the current analysis, the following simplifying assumptions are used as follows: 
- The working fluid is a steady laminar flow.

- The properties of the working fluid (air) are constant.

- The fluid viscous dissipation and body forces are neglected.

Table 1. List of governing equations

\begin{tabular}{cccc}
\hline Equation & $\varphi$ & $\Lambda_{\varphi}$ & $\mathrm{S}_{\varphi}$ \\
\hline Continuity & 1 & 0 & 0 \\
x-momentum & $\mathrm{u}$ & $\mu / \rho$ & $\frac{-1}{\rho} \frac{\partial p}{\partial x}$ \\
y-momentum & $\mathrm{v}$ & $\mu / \rho$ & $\frac{-1}{\rho} \frac{\partial p}{\partial y}$ \\
Energy & $\mathrm{T}$ & $\frac{k}{\rho c p}$ & 0 \\
\hline
\end{tabular}

The boundary conditions are as follows:

- Inlet ( $\mathrm{u}=\mathrm{uin}, \mathrm{v}=0)$, Tin $=300 \mathrm{k}$

- Outlet $\left(\frac{\partial u}{\partial x}=\frac{\partial v}{\partial y}=0\right.$ and $\frac{\partial p}{\partial x}=0$

- Walls of the channel and vortex generators (no-slip velocity with $\mathrm{Tw}=400 \mathrm{k}$ and $\mathrm{TVG}=300 \mathrm{k}$ )

\section{NUMERICAL METHOD}

\subsection{Grid independency}

To identify a suitable grid in terms of computational time and cost, a grid-independent test is introduced. This includes examining five various non-uniform grids at $\mathrm{Re}=500$. A nonuniform grid is applied to obtain an appropriate solution for the considered problem of a 2-D rectangular channel with VGs. Figure 3 shows that the average Nusselt number is almost constant after using the third grid of 150000 . Therefore, the grid of 159632 is selected to be used in this study.

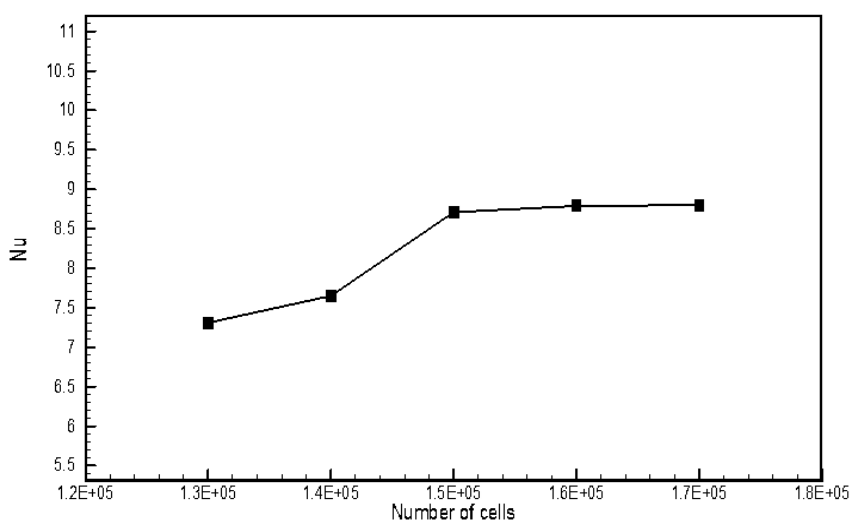

Figure 3. Grid independent test

Two-dimensional structured mesh of triangle elements distributed with more density near channel walls and around vortex generators as shown in Figure 4.

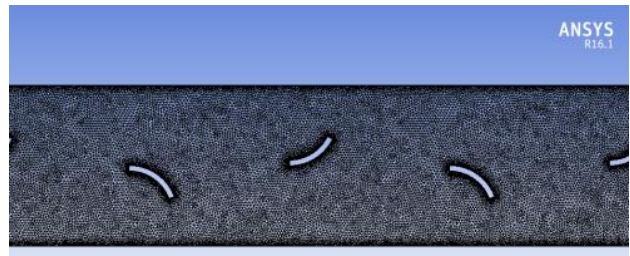

Figure 4. Grid generation
The equations are discretized using the control volume method with a SIMPLIC algorithm scheme to couple the velocity and pressure.

\subsection{Model validation}

The numerical results of the current model are validated by comparing the local and average Nusselt numbers and the friction factor of a plane channel without VGs with Khan and Li [16] as shown in Figure 5(a), (b) and (c). Figure 5 shows a good agreement between the current numerical results and the results of Khan and Li [16].

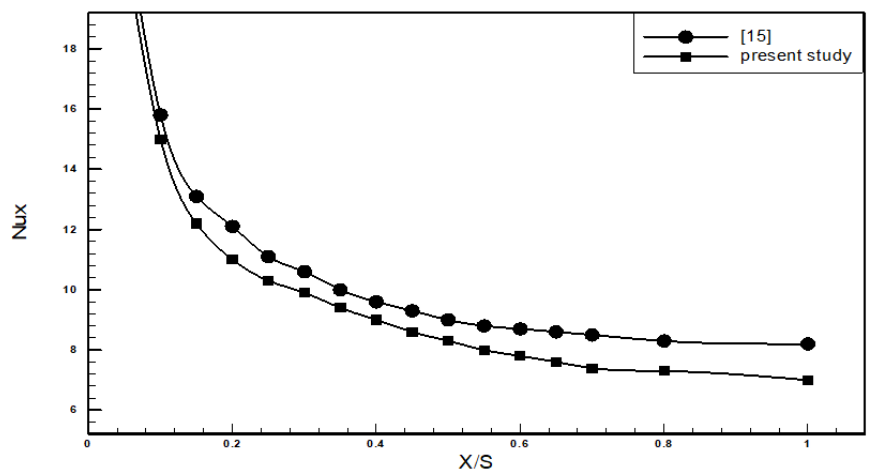

(a)

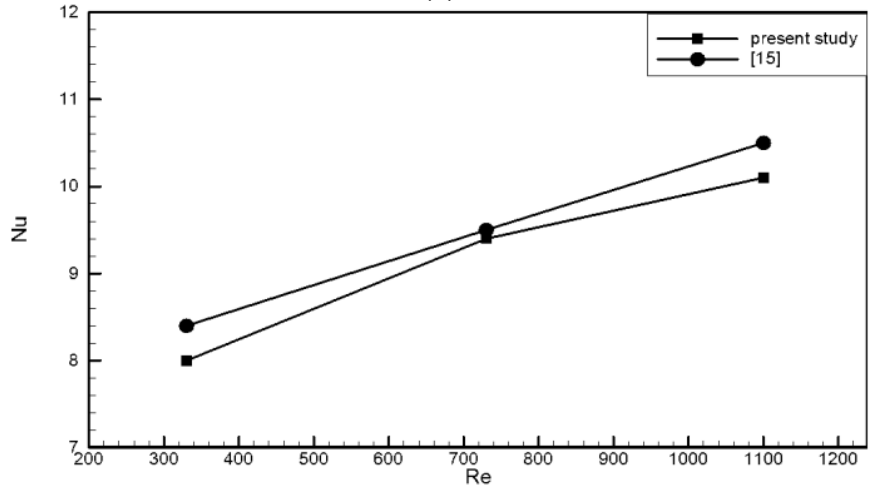

(b)

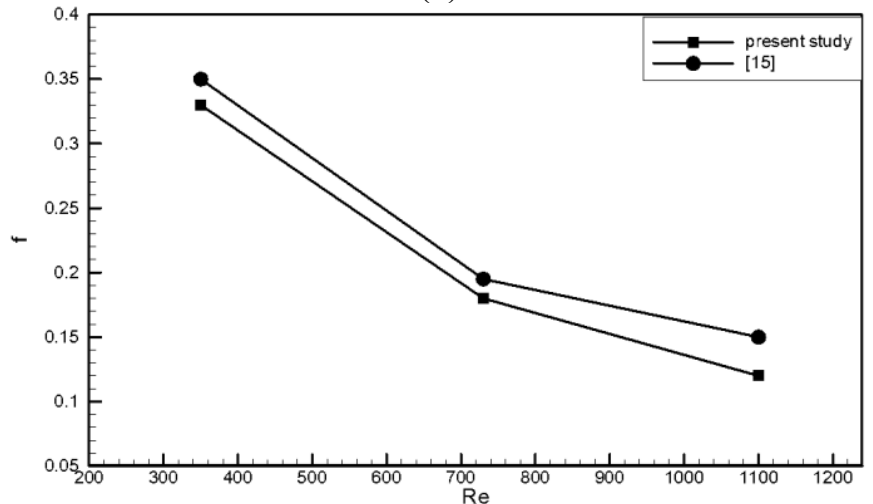

(c)

Figure 5. Comparison of the present numerical results with Khan and Li [16] for, (a) Local Nu, (b) Average $\mathrm{Nu}$ and (c) Friction factor

The Reynold number, friction factor and Nusselt number are defined as:

$$
R e=\frac{\rho u H}{\mu}
$$




$$
\begin{gathered}
c f=\frac{2 p H}{\rho U^{2} L} \\
N u=\frac{h H}{K}
\end{gathered}
$$

In order to assess the effect of the proposed VGs on the overall heat transfer performance of the plain channel, the following parameter is used as in [30]:

$$
\text { performance }=\left(\frac{N u}{N u_{o}}\right) /\left(\frac{c f}{c f_{o}}\right)
$$

\section{RESULTS}

Figure 6 shows the temperature contours using the proposed concave VGs, type 1 on the right and type 2 on the left, at $\mathrm{d} / \mathrm{H}=1$ with different values of Reynolds number. From Figure 6 , it can be clearly seen that the proposed VGs affects the temperature distribution along the channel. The figure shows that the use of VGs affects the temperature contour due to the directed flow towered the channel walls and the thickness of the boundary layer (BL) will be decreased due to the increase in velocity especially in type 1 . The effect of Reynolds number on temperature distribution can be clearly shown in the figure for both types of VGs. The increase in Reynolds number leads to an increase in the sweeping of the heat removed from the channel walls and improvement in the fluid mixing process.
Lower values of the temperature contours were observed behind type $2 \mathrm{VG}$ compared to type 1 resulting from its lower curvature which leads to a delay in separating the flow. The figure also shows that the effect of VGs is decreased toward the outlet of the channel as the rate of heat transfer between the heated walls and fluid flow increases along the channel.

Contours of velocity distribution through the channel using the proposed VGs, type 1 on the left and type 2 on the right, at $\mathrm{d} / \mathrm{H}=1$ with different values of Reynolds number are shown in Figure 7. It can be clearly seen that, increasing Re results in high values of the velocity contours for both types of VGs. The velocity fields are affected by the use of VGs. This effect is more pronounced using type 1 compared to type 2 due to the increase in the concave shape of the former. The figure shows that the flow moves toward the walls of the channel due to the existence of the VGs located in the center of the channel which changes the direction of the inlet fluid flow. Higher velocity can be observed at the tip of the VGs due to decrease in the area between the VGS and channel walls. This is more pronounced by increasing Reynolds number. The vortices behind the VGs are very clear and they increase by the use of type 1 VG, at high Reynolds number, due to separation of flow at the tip of these VGs.

Figure 8 shows the wake generated behind vortex generator type 2. From the figure, it is can be seen that the flow undulating occurring behind the vortex generator is similar to the undulating appear due to the movement of the fish, which leads to fluid turbulence and thus to an improvement in the fluid mixing process.
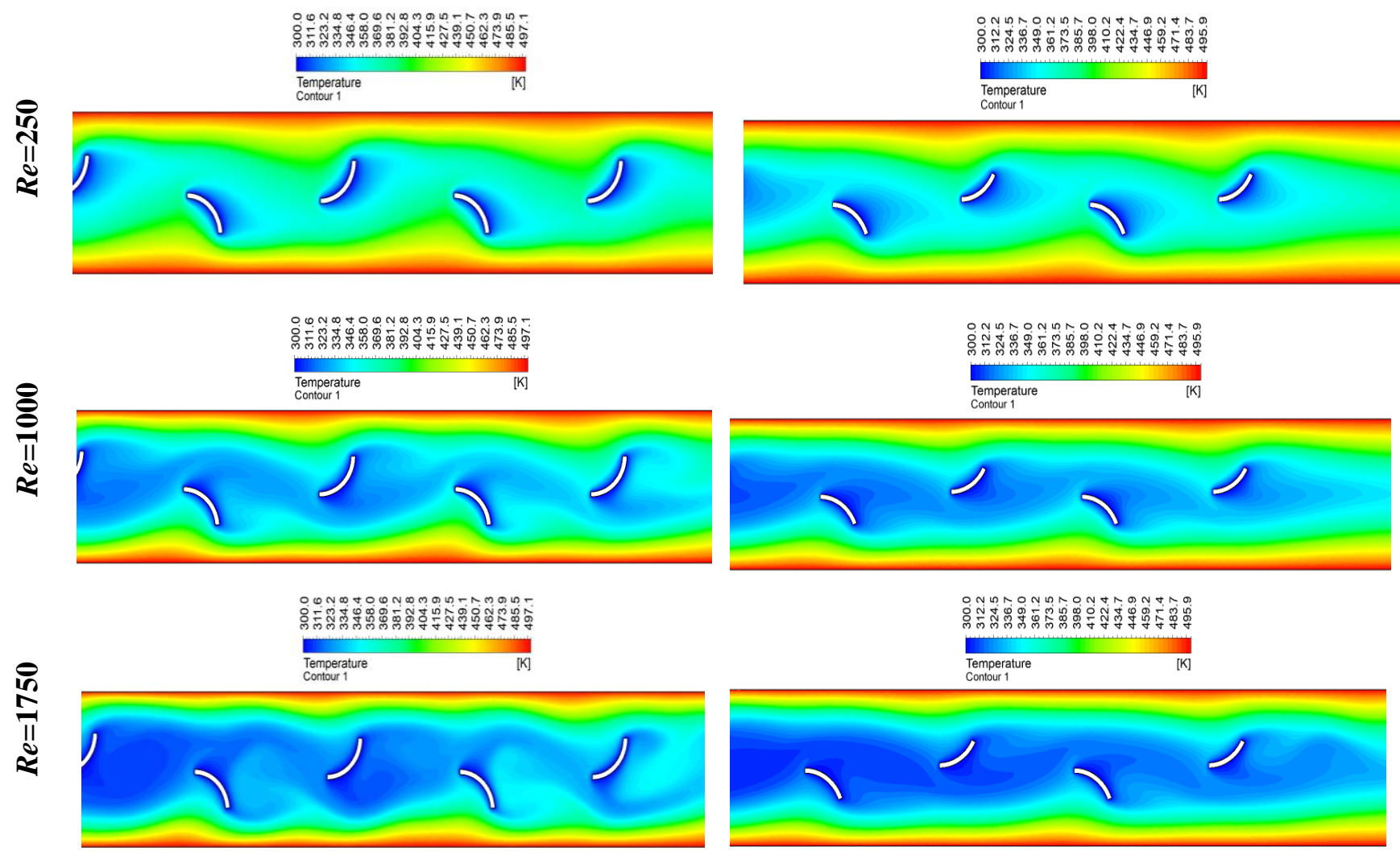

Figure 6. Temperature contours using the proposed vortex generators, type 1 on the left and type 2 on the right, at $\mathrm{d} / \mathrm{H}=1$ with different values of Reynolds number $(250,1000,1750)$ 


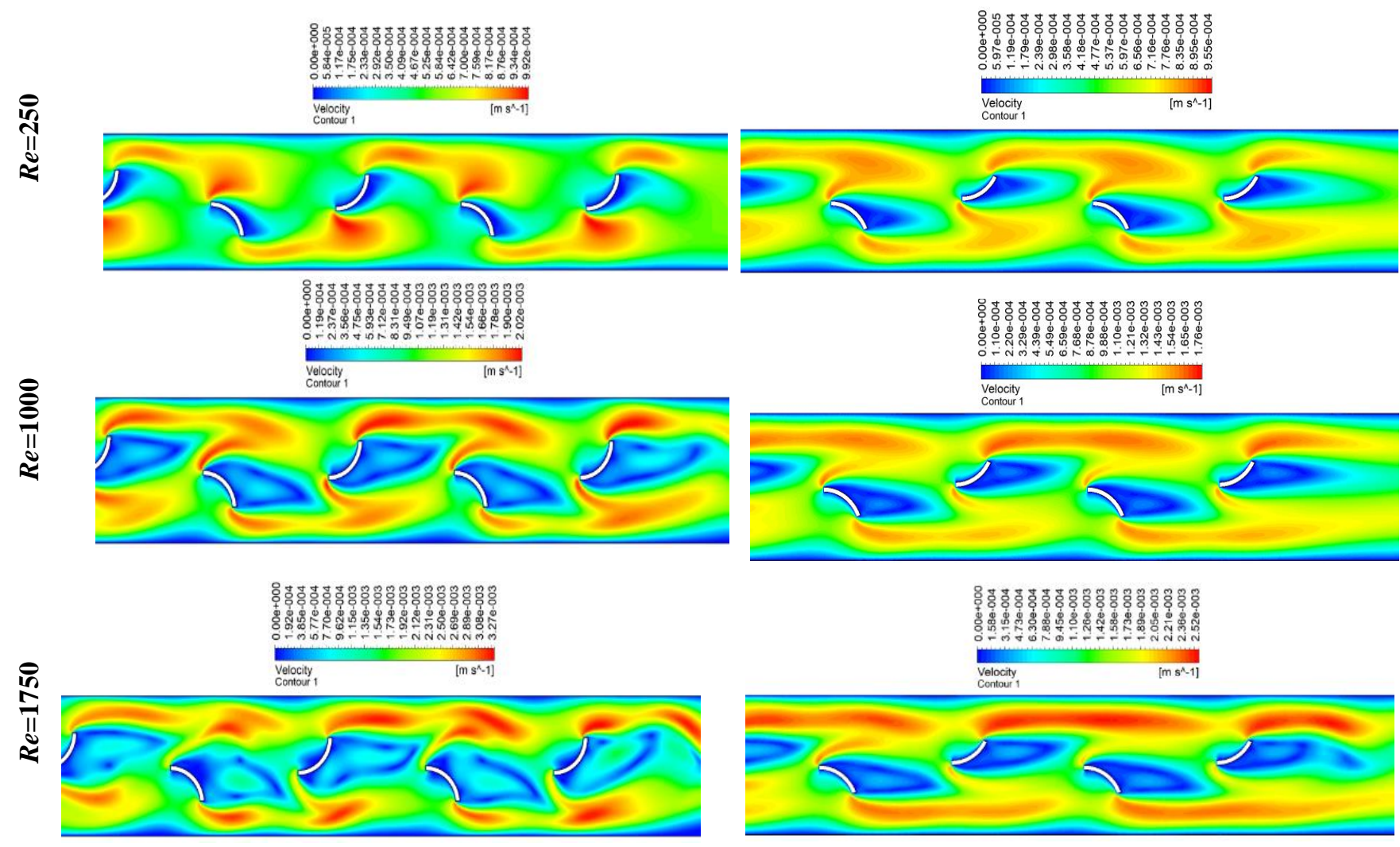

Figure 7. Velocity contours using the proposed vortex generators, type 1 on the left and type 2 on the right, at $\mathrm{d} / \mathrm{H}=1 \mathrm{with}$ different values of Reynolds number $(250,1000,1750)$

(a)

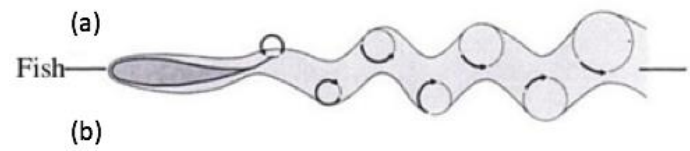

(b)

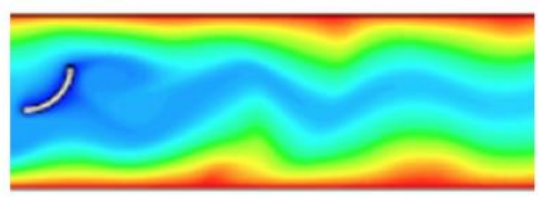

Figure 8. Wakes behind vortex generator (a) swimming fish and (b) vortex generator type 2

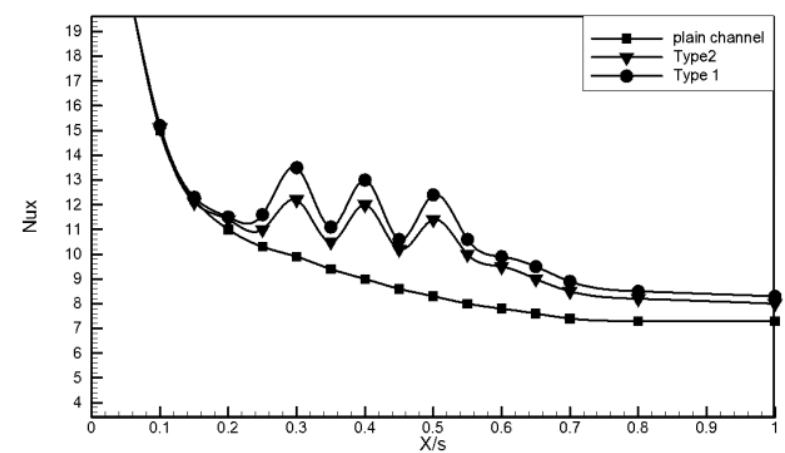

Figure 9. Local Nusselt number along the channel with and without using VGs

Heat transfer in terms of the local Nusselt number along the upper wall of the channel with the use of both proposed vortex generators at $d / H=1$ and $\mathrm{Re}=750$ is shown in Figure 9. It clearly shows that the local Nusselt number increases by the use of the VGs due to increasing heat sweeping from the heated wall. The maximum heat transfer is obtained using type 2 VG due to increasing longitudinal vortices in the flow behind this vortex generator.

Figure 10 compares the heat transfer rate using both types of VGs with $R e$ at different distances between these VGs. Figure 9 shows that the heat transfer rate increases by increasing $R e$. It is also shown that using type $1 \mathrm{VG}$ is more effective than type 2 for all considered distances. The increase in the distance $(\mathrm{d} / \mathrm{H})$ can clearly enhance the overall heat transfer.

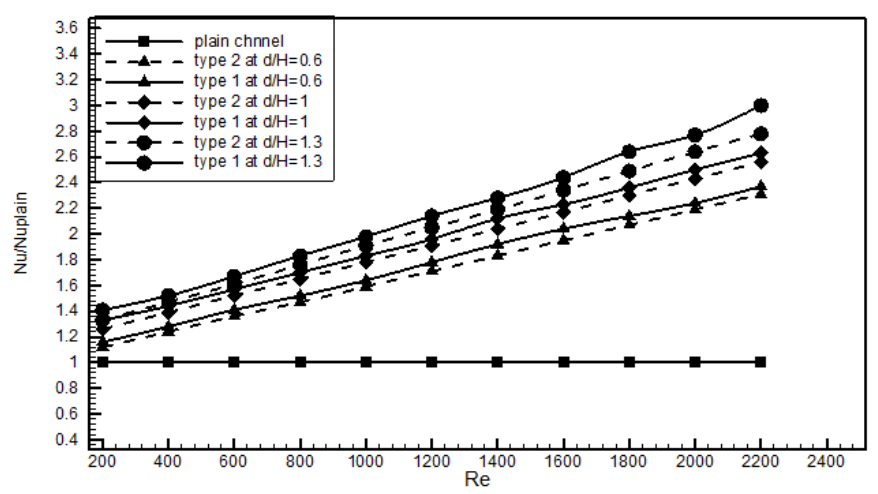

Figure 10. Effect of the distance $(\mathrm{d} / \mathrm{H})$ of the VGs with $R e$ on heat transferccc

Figure 11 indicates the variation of the performance as a function of Re. It is found that the performance of the channel with the use of VGs is higher than the plain channel. The performance increases with increasing Re. This is because both types of VGs generate vortices which in turn results in mixing the heated flow near the walls with the cold flow 
sweeping the heat from walls to the fluid flow, also the figure shows that type 1 is more effective than type 2 as the former leads to an increase in the amount of the fluid towards the heated walls.

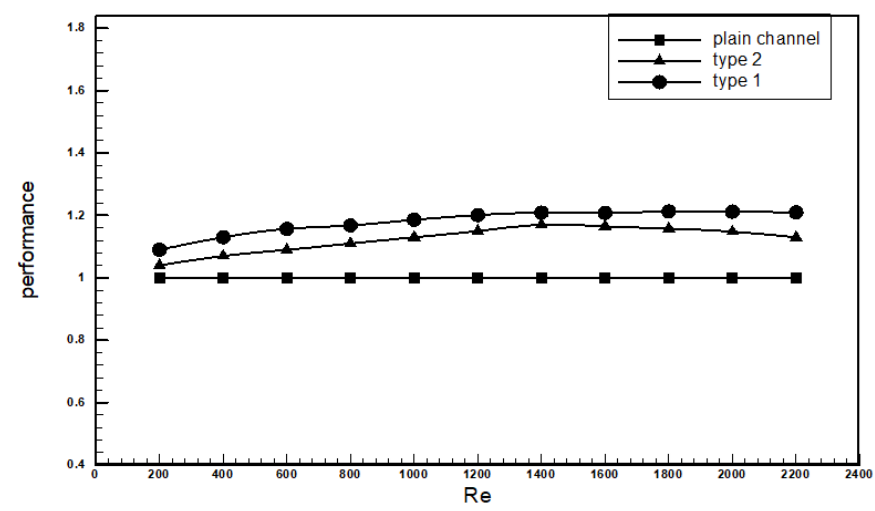

Figure 11. Effect of $R e$ on performance using VGs

\section{CONCLUSIONS}

Two-dimensional simulation ware performed to study the effect of two types of concave vortex generators, arranged inline as fish-tail locomotion, on heat transfer in the channel.

The proposed arrangement of the VGs aimed to decrease the pressure drop in the channel and enhance the heat transfer by generating staggered vortices with undulation flow across the channel.

A commercial CFD package FLUENT 16.1 was used to solve continuity, momentum, and energy equations using SIMPLIC method with a prorated boundary conditions at Reynolds number ranges of (200-2200) with changing the distance between VGs. It was shown that heat transfer performance was enhanced by the use of the proposed vortex generators within the range of (4-21.1). The use of type $1 \mathrm{VG}$ is more effective in terms of heat transfer enhancement and the reduction of the friction factor.

\section{REFERENCES}

[1] Fiebig, M., Valencia, A., Mitra, N.K. (1993). Wing-type vortex generators for fin-and-tube heat exchangers. Experimental Thermal and Fluid Science, 7(4): 287-295. https://doi.org/10.1016/0894-1777(93)90052-K

[2] He, Y.L., Chu, P., Tao, W.Q., Zhang, Y.W., Xie, T. (2013). Analysis of heat transfer and pressure drop for fin-and-tube heat exchangers with rectangular winglettype vortex generators. Applied Thermal Engineering, 61(2): $770-783$ https://doi.org/10.1016/j.applthermaleng.2012.02.040

[3] Lu, G., Zhai, X. (2019). Analysis on heat transfer and pressure drop of a microchannel heat sink with dimples and vortex generators. International Journal of Thermal Sciences, 145:

105986. https://doi.org/10.1016/j.ijthermalsci.2019.105986

[4] Nfawa, S.R., Talib, A.R.A., Masuri, S.U., Basri, A.A., Hasini, H. (2019). Heat transfer enhancement in a corrugated-trapezoidal channel using winglet vortex generators. CFD Lett, 11: 69-80.

[5] Eibeck, P.A., Eaton, J.K. (1987). Heat transfer effects of a longitudinal vortex embedded in a turbulent boundary layer. ASME. J. Heat Transfer. February, 109(1): 16-24. https://doi.org/10.1115/1.3248039

[6] Biswas, G., Chattopadhyay, H. (1992). Heat transfer in a channel with built-in wing-type vortex generators. International Journal of Heat and Mass Transfer, 35(4): 803-814. https://doi.org/10.1016/0017-9310(92)90248Q

[7] Mitra, N.K., Fiebig, M. (1993). Experimental investigations of heat transfer enhancement and flow losses in a channel with double rows of longitudinal vortex generators. International Journal of Heat and Mass Transfer, $36(9)$ : https://doi.org/10.1016/S0017-9310(05)80117-6

[8] Wang, Q., Chen, Q., Wang, L., Zeng, M., Huang, Y., Xiao, Z. (2007). Experimental study of heat transfer enhancement in narrow rectangular channel with longitudinal vortex generators. Nuclear Engineering and Design, 237(7): 686-693. https://doi.org/10.1016/j.nucengdes.2006.09.003

[9] Wu, J.M., Tao, W.Q. (2008). Numerical study on laminar convection heat transfer in a rectangular channel with longitudinal vortex generator. Part A: Verification of field synergy principle. International Journal of Heat and Mass Transfer, 51(5-6): 1179-1191. https://doi.org/10.1016/j.ijheatmasstransfer.2007.03.032

[10] Wu, J.M., Tao, W.Q. (2008). Numerical study on laminar convection heat transfer in a channel with longitudinal vortex generator. Part B: Parametric study of major influence factors. International Journal of Heat and Mass Transfer, 51(13-14): 3683-3692. https://doi.org/10.1016/j.ijheatmasstransfer.2007.03.031

[11] Tang, L.H., Chu, W.X., Ahmed, N., Zeng, M. (2016). A new configuration of winglet longitudinal vortex generator to enhance heat transfer in a rectangular channel. Applied Thermal Engineering, 104: 74-84. https://doi.org/10.1016/j.applthermaleng.2016.05.056

[12] Oneissi, M., Habchi, C., Russeil, S., Bougeard, D., Lemenand, T. (2016). Novel design of delta winglet pair vortex generator for heat transfer enhancement. International Journal of Thermal Sciences, 109: 1-9. https://doi.org/10.1016/j.ijthermalsci.2016.05.025

[13] He, J. (2013). Vortex-enhanced heat transfer by a new delta-winglet array. Doctoral dissertation, University of Illinois at Urbana-Champaign. http://hdl.handle.net/2142/42142.

[14] Rütten, M., Krenkel, L. (2010). Vortex-generator pairs for vortex-induced heat-transfer enhancement in heatexchanger channels. In New Results in Numerical and Experimental Fluid Mechanics, VII: 555-562. http://dx.doi.org/10.1007/978-3-642-14243-7_68

[15] Khan, T.A., Li, W. (2018). Optimal configuration of vortex generator for heat transfer enhancement in a platefin channel. Journal of Thermal Science and Engineering Applications, 10(2). https://doi.org/10.1115/1.4038418

[16] Maniar, N.C. (2013). Heat Transfer Enhancement in a Rectangular Channel Using Vortex Generator in a Laminar Flow.

[17] Bayareh, M., Nourbakhsh, A., Khadivar, M.E. (2018). Numerical simulation of heat transfer over a flat plate with a triangular vortex generator. International Journal of Heat and Technology, 36(4): 1493-1501. https://doi.org/10.18280/ijht.360443

[18] Syaiful, Sugiri, G., Soetanto, M.F., Bae, M.W. (2017). Effect of concave rectangular winglet vortex generator 
on convection coefficient of heat transfer. In AIP Conference Proceedings, 1788(1): 030025. https://doi.org/10.1063/1.4968278

[19] Su, M.T., Sinaga, N., Wulandari, R., Bae, M.W. (2018). Effect of perforated concave delta winglet vortex generators on heat transfer augmentation of fluid flow inside a rectangular channel: An experimental study. In MATEC Web of Conferences, 204: 04015. https://doi.org/10.1051/matecconf/201820404015

[20] Chompookham, T., Thianpong, C., Kwankaomeng, S., Promvonge, P. (2010). Heat transfer augmentation in a wedge-ribbed channel using winglet vortex generators. International Communications in Heat and Mass Transfer, 37(2): 163-169. https://doi.org/10.1016/j.icheatmasstransfer.2009.09.01 2

[21] Morjan, S., Jawad, B.A., Liu, L., Yee, K., Fernandez, V. (2016). Investigation of the effect of vortex generation on heat transfer enhancement in horizontal channel flow. In ASME International Mechanical Engineering Congress and Exposition, 50626: V008T10A082. American Society of Mechanical Engineers. https://doi.org/10.1115/IMECE2016-65446

[22] Zheng, Y., Yang, H., Mazaheri, H., Aghaei, A., Mokhtari, N., Afrand, M. (2020). An investigation on the influence of the shape of the vortex generator on fluid flow and turbulent heat transfer of hybrid nanofluid in a channel. Journal of Thermal Analysis and Calorimetry, 1-14. https://doi.org/10.1007/s10973-020-09415-2

[23] Ahmed, H.E., Mohammed, H.A., Yusoff, M.Z. (2012). Heat transfer enhancement of laminar nanofluids flow in a triangular duct using vortex generator. Superlattices and Microstructures, 52(3): 398-415. https://doi.org/10.1016/j.spmi.2012.05.023

[24] Alhumoud, J.M., Almashan, N. (2020). Enhanced hydrodynamic performance of fluid flow in a rectangular channel using baffles with gaps. International Journal of Heat and Technology, 38(1): 187-202. https://doi.org/10.18280/ijht.380121

[25] Aidaoui, L., Lasbet, Y., Loubar, K. (2016). Numerical analysis of the parameters governing 3D laminar mixed convection flow in a rectangular channel with imposed wall flux density. International Journal of Heat and Technology, 34(4): 581-589. https://doi.org/10.18280/ijht.340405

[26] Menni, Y., Chamkha, A.J., Zidani, C., Benyoucef, B. (2019). Numerical analysis of heat and nanofluid mass transfer in a channel with detached and attached baffle plates. Math Model Eng Probl, 6(1): 52-60. https://doi.org/10.18280/mmep.060107

[27] Namshad, T., Shrivastava, M., Agrawal, A., Sharma, A. (2017). Effect of wavelength of fish-like undulation of a hydrofoil in a free-stream flow. Sādhanā, 42(4): 585-595. https://doi.org/10.1007/s12046-017-0619-7

[28] Gang, X., Liu, Y., Si, W., Xue, Y., Guo, F., Li, Z. (2020). Evolvement rule and hydrodynamic effect of fluid field around fish-like model from starting to cruising. Engineering Applications of Computational Fluid Mechanics, 14(1): 580-592. https://doi.org/10.1080/19942060.2020.1734095

[29] Ebrahimi, A., Roohi, E., Kheradmand, S. (2015). Numerical study of liquid flow and heat transfer in rectangular microchannel with longitudinal vortex generators. Applied Thermal Engineering, 78: 576-583. https://doi.org/10.1016/j.applthermaleng.2014.12.006

[30] Ebrahimi, A., Kheradmand, S. (2012). Numerical simulation of performance augmentation in a plate fin heat exchanger using winglet type vortex generators. International Journal of Mechanical Engineering and Mechatronics, 1(2): 109-121. https://doi.org/10.11159/ijmem.2012.014

\section{NOMENCLATURE}

Cp Static pressure coefficient

d Distance between vortex generator $(\mathrm{m})$

F Mass flux

$\mathrm{H} \quad$ Height of channel (m)

h Coefficient of heat transfer $\left(\mathrm{W} / \mathrm{m}^{2} . \mathrm{K}\right)$

k Thermal conductivity (W/m. K)

L Channel length (m)

$\mathrm{Nu}$ Nusselt number

P Pressure $\left(\mathrm{N} / \mathrm{m}^{2}\right)$

Re Reynolds number

$\mathrm{S}$ distance between the first and the last vortex generator (m)

$\mathrm{T} \quad$ Temperature $(\mathrm{K})$

$\mathrm{u} \quad$ Velocity in the $\mathrm{x}$-direction $(\mathrm{m} / \mathrm{s})$

$\mathrm{v}$ Velocity in the $y$-direction $(\mathrm{m} / \mathrm{s})$

$\mathrm{x}, \mathrm{y}$ Cartesian coordinates (m)

$\mathrm{Nu}_{o}$ Nusselt number for the plain channel

$\mathrm{Cf}_{\mathrm{o}}$ The friction coefficient for plain channel

2-D Two dimensions

VG Vortex generator

BL Boundary layer 